\title{
Blockchain Technology Adoption, Benefit and Challenges for Halal Food Traceability
}

\author{
Tasnim Nikmatullah R ${ }^{1 *}$, Made Iska A ${ }^{2}$, Yudhi Anggoro ${ }^{3}$ \\ ${ }^{1}$ STIE Indocakti, Indonesia \\ ${ }^{2}$ STIE Indocakti, Indonesia \\ ${ }^{3}$ STIE Indocakti, Indonesia \\ *Correspoding author.Email: tasnimnikmatullah3876@gmail.com
}

\begin{abstract}
The traceability of halal food has in turn increasingly become the focus of attention of researchers, business actors and stakeholders. Various benefits can be obtained from strengthening the halal food tracking system. This technology system is a form of digital transformation of supply chain management from traditional methods.. The added value of using the search technology is worthy of being a strong reason to start the technology adoption process. By using the literature review method, this paper seeks to reveal the benefits and challenges of the adoption of traceability technology for tracing halal food. Many important benefits will be obtained when business actors move from traditional supply chain management to digital supply chain. In general, these obstacles are related to the lack of regulation, the lack of understanding of most business actors related to blockchain technology, constraints related to costs.
\end{abstract}

Keywords: Blockchain Technology, Halal Food Traceability, Technology Adoption

\section{INTRODUCTION}

In recent years, the halal business has continued to experience significant growth. According to the Pew Research Center, the Muslim population in 2015 reached 1.8 billion people, 24.1 percent of the world's total population. Consumers' concern for the halalness of a product, especially food products, has now been increasing along with the strengthening of community religiosity and reasons of hygiene and health. Starting from the high public demand for the assurance of halal assurance of food and beverage products, as a consequence, tracing the certainty of halal throughout the process from procurement of materials, production, equipment, distribution systems is an important domain of discussion. The halal industry is an industry that uses rigorous analytical methods to include inspection and certification at every stage of production to ensure that products are not contaminated with non-halal substances or processes. To fulfill the halal aspect, a product must be ensured that it is clean and hygienic in the production process and contains only ingredients that are also halal [1]
Islam has formulated a series of rules in preparing and serving food, that the source, process, provision of food must be following the principles of the Islamic religion [2]. The concept and terms of halal itself include: 1) cleanliness and hygiene in food preparation because both of criteria and security are part of religion, food that meets these criteria is under the commandments of Allah SWT and is allowed to be consumed [3], 2) utensils, equipment, all surfaces that come into contact with food must be clean and sterile from non halal material to avoid contamination of haram material [4]. Maintaining the halalness of products from raw materials, processes, to products reaching consumers is a challenge for business actor. This paper presents the results of the identification of various benefits and challenges which are formulated through a literature review approach. Articles that discuss the benefits and challenges of using blockchain technology are presented and discussed to obtain answers to research problems. 


\section{LITERATURE REVIEW}

\subsection{Blockchain Technology Adoption}

Blockchain technology originates from Distributed Ledger Technology, which facilitates peer-to-peer transactions without the need for intermediaries or centralized authorities [5]. With the use of blockchain, it is possible to track the entire supply chain in a few seconds [6]. Blockchain has the potency to be a tool that can increase the transparency, traceability and sustainability of food supply chains. [7] Several studies have found numerous elements that influence the intention to embrace blockchain technology in the context of supply chains in general. Consumer demand and the need for food tracing are factors that encourage the adoption of blockchain technology [8] Competitive pressure, Complexity cost and relative [9], Environmentrelated, Technological-related, Organizational-related [10], Facilitating conditions, Social influence, Trust, Effort expectancy [11], further [12] Dual trust, data transparency, data immutability, inter - operability, product characteristics, social power, and behavioural control are all key factors that influence the adaptability of Blockchain Technology in the Supply Chain. The factors that influence the adoption of blockchain technology are economic and social-cultural.

\subsection{Benefits and Challenges}

Some variables that drive blockchain adoption are ambiguous, offering both advantages and risks: the transparency of information in blockchain-based systems poses issues with non-public protection. Blockchain's non-reversibility procedures result in error intolerance. [13].

In the notion of halal food supply chain management, the availability of real-time data that can be accessed in a secure environment is critical. They identified four key advantages of blockchain technology: transparency, efficiency, security, and safety, all of which provide context to a finished product or service [14]. The ability of BT to provide visibility, operational improvements, and secure record keeping adds to its importance. The most important aspect is that it assures that data records in a supply chain are of high quality, consistent, and tamper-proof. [15]. It could be used to increase supply chain efficiency by increasing demand and supply information visibility, as well as supply chain coordination and trust-building. [16]

Besides the various benefits of utilizing blockchain technology, several barriers that might influence the adoption process were identified in various studies. Due to the lack of a worldwide regulated or unified Halal certification system, Halal goods cross-border trade between multinational economies has been hampered. Each country's Halal certification authority and set of rules are distinctive [17], there is no unified perception of how the government can be involved and collaborate with the private sector in the development of a digitalbased supply chain ecosystem. Insufficient knowledge of distributed ledger technology, technological issues, data tampering, difficulty involving stakeholders, and a lack of legislation have all been mentioned as potential barriers to blockchain implementation [18]. Disintermediation, cost and security challenges, and technological and cultural complexity, High prices, particularly at the start of the blockchain technology's deployment, remain an obstacle to its widespread adoption. [19] was identified the future challenges to applied blockchain technology: (1) the changes of consumer preference about the rapid access of information, (2) the difference and overlapping regulation from regulators around the world, (3) the lack of unifying requirements, (4) the differences on the traceability varies based on the industry or product, (5) simply a lack of records, (6) the weakness of technical systems

\section{METHODOLOGY}

This study will use a literature review to highlight the different advantages of employing blockchain technology in the search for halal food, as well as the numerous problems that may be encountered. The study's depth is determined by a review of the relevant literature.

\section{RESULT AND DISCUSSION}

The results of the literature review reveal several benefits of adopting blockchain technology in supply chain management as a halal product tracing system. In a public blockchain, every transaction is accessible to everyone on the network. The data is kept and monitored on a blockchain by all participants of the supply chain network, providing transparency and trust to even the most complicated supply networks [20]. Transparency is used in supply chain traceability to operationalize organizational goals related to raw material sources and give context to a final product or service. To increase supply chain efficiency, blockchain technology might be used for demand and supply information visibility, supply chain coordination, and trust-building [16]. The desentralized personal data management system boosted the efficiency of blockchain by using off-chain data storage and heavy processing, where blockchain has the power to improve the security of privacy sensitive data since the system protects the user ownership of their data. [20]

The advantages and disadvantages of putting blockchain into place and/or employing it in the food 
supply chain are examined. Intra-organizational, interorganizational, system-related, and external hurdles to Blockchain adoption in supply chain management are classified by [21]] and [22]. External obstacles are problems that parties outside of the food supply chain, such as institutions or the government, encounter since they do not immediately profit from its actions [22]. Participants in a complicated supply chain, such as food, may be dispersed throughout many locations, each with its own set of laws and regulations. [23]

\section{CONCLUSION}

Many important benefits will be obtained when business actors move from traditional supply chain management to blockchain technology. Transparency, efficiency, expansion of market share are the most important thing in the context of the Halal Food Supply Chain. Blockchain technology adoption will make the company easier to track and trace the source, process, location of raw material.. In general, these obstacles are related to the lack of regulation, the lack of understanding of most business actors related to blockchain technology, constraints related to costs. he government must play the most active role possible in encouraging businesses to migrate from traditional supply networks to more digital supply chains by implementing blockchain technology.

\section{AUTHOR CONTRIBUTIONS}

This work was carried out in collaboration between three authors. Author Made Iska wrote the first draft of the paper. Author Tasnim read, corrected and structured the paper. Author Yudhi Anggoro read, corrected and structured the paper. All of authors read and approved the final manuscript

\section{ACKNOWLEDGMENTS}

We express our gratitude to colleagues and the article writing team for their encouragement and contributions of ideas and recommendations. We express our gratitude to the STIE Indocakti professors for their assistance and enthusiasm.

\section{REFERENCES}

[1] N. Ab Rashid and J. Bojei, "The Relationship Between Halal Traceability System Adoption and Environmental Factors of Halal Food Supply Chain Integrity in Malaysia," Journal of Islamic Marketing, vol. 11, no. 1, pp. 117-142, 2019.

[2] Z. Samori, A. Ishak and N. Kassan, "Understanding the development of Halal Food Standard Suggestion for Future Research," International Journal of Social Science and Humanity, vol. 4, no. 6, 2014.

[3] A. Ambali and A. Bakar, "People's Awareness on Halal Foods and Products: Potential Issues for
Policy Makers," in International Halal Conference, Kuala Lumpur, 2014.

[4] Henderson J, "Halal Food, Certification and Halal Tourism: Insight from Malaysia," Tourism Management Perspectives.

[5] M. Rennock, A. Cohn and J. Butcher, "Blockchain Technology and Reglatory Investigations," The Journal Litigation, pp. 35-45, 2018.

[6] F. Yiannas, "A New Era of Food Transparency Powered by Blockchain," Innovation, vol. 12, no. 1, 2018.

[7] S. Ahmed and N. Broek, "Food Supply chain: Blockchain Could Boost Food Security," Nature, vol. 550, no. 7674, p. 43, 2017.

[8] D. Bumblauskan, A. Mann, B. Dugan and J. Rittmer, "A Blockchain Use Case in Food Distribution: Do You Know Where Your Food Has Been?," International Journal of Information Management, 2019.

[9] Y. Wang, M. Singgih, J. Wang and M. Rit, "Making Sense of Blockchain Technology: (How) Will it Transform Supply Chains?," International Journal of Production Economics, 2019.

[10] E. Gokalp, "Blockchain Based Suplly Chain Management: Understanding the Determinants of Adoption in the Context of Organization," Information System Management, 2020.

[11] M. Querioz, S. F. Wamba, M. De Bourmont and R. Telles, "Blockchain Adoption in Operations and Supply Chain Management: Empirical Evidence from an Emerging Economy," International Journal of Production Research.

[12] D. Ghode, V. Yadav, R. Jain and G. Soni, "adoption Blockchain in Supply Chain: an Analysis on Influencing Factors," Journal of Enterprise Information Management, vol. 33, no. 3, pp. 437456, 2020.

[13] S. Chen, X. Liu, J. Yan, G. Hu and Y. Shi, "Processes, benefts, and challenges for adoption of Blockchain Technologies in Food Supply Chains: a Thematic Analysis," Information System and eBusiness Management, 2020.

[14] K. Francisco and D. Swanson, "The Supply Chain Has No Clothes: Technology Adoption of Blockchain for Supply Chain Transparency," logistics, vol. 2, no. 2, 2018.

[15] Y. Wang, M. Singgih, J. Wang and M. Rit, "Making Sense of Blockchain Technology: How Will it Transform Supply Chains?," International Journal 
of Production Economics, vol. 211, pp. 221-236, 2019.

[16] T.-M. Choi, "Blockchain Technology-Supported Platforms for Diamond Authentication and Certification in Luxury Supply Chain," Transportation Research Part E, vol. 128, pp. 17-29, 2019.

[17] A. Tan, D. Gligor and A. Ngah, "Applying Blockchain for Halal Food Traceability," International Journal of Logistic Research and Application, 2020.

[18] J. Duan, C. Zhang, Y. Gong, S. Brown and Z. Li, "A Content-Analysis Based Literature Review in Blockchain Adoption Within Food Supply Chain," International Journal of Environmental Research and Public Health, vol. 17, no. 84, 2020.

[19] J. Galves, J. Mejuto and J. Simal-Gandra, "future Challenges on The use of Blockchain for Food Traceability Analysis," Trends in Analytical Chemistry, vol. 107, pp. 222-232, 2018.

[20] G. Zyskind, O. Nathan and A. S. Pentland, "Enigma: Decentralized Computation Platform with Guaranteed Privacy," in New Solution for Cybersecurity, Cambridge, The MIT Press, 2018.

[21] F. Tian, "A supply chain traceability system for food safety based on HACCP, blockchain \& Internet of things," in International Conference of Service System and Service Management, Dalian, 2017.

[22] S. Saberi, M. Kouhizadeh, J. Sarkis and L. Shen, "Blockchain Technology and its Realtionship to Sustainable supply chain management," International Journal of Production Research, vol. 57, no. 7, pp. 2117-2135, 2019.

[23] R. Cole, M. Stevenson and J. Aitken, "Blockchain Technology Im[lications for Operations and Supply Chain Management," Supply Chain Management: An International Journal, vol. 24, no. 4, pp. 469-483, 2019. 